\title{
Increasing secure base script knowledge among parents with Attachment and Biobehavioral Catch-up
}

\author{
K. Lee Raby ${ }^{1}$ (D), Theodore E. A. Waters ${ }^{2}$, Alexandra R. Tabachnick ${ }^{3}$, Lindsay Zajac ${ }^{3}$ and Mary Dozier ${ }^{3}{ }_{1}$ \\ ${ }^{1}$ Department of Psychology, University of Utah, Salt Lake City, USA; ${ }^{2}$ Department of Psychology, New York University - Abu Dhabi, Abu Dhabi, UAE and ${ }^{3}$ Department \\ of Psychological and Brain Sciences, University of Delaware, Newark, USA
}

\begin{abstract}
This study evaluated whether Attachment and Biobehavioral Catch-up (ABC), a parenting intervention, altered the attachment representations of parents (average age of 34.2 years) who had been referred to Child Protective Services (CPS) due to risk for child maltreatment when their children were infants. Approximately 7 years after completing the intervention, parents who had been randomized to receive ABC $(n=43)$ exhibited greater secure base script knowledge than parents who had been randomized to receive a control intervention $(n=51)$. Low-risk parents $(n=79)$ exhibited greater secure base script knowledge than CPS-referred parents who had received a control intervention. However, levels of secure base script knowledge did not differ between low-risk parents and CPS-referred parents who had received the $\mathrm{ABC}$ intervention. In addition, secure base script knowledge was positively associated with parental sensitivity during interactions with their 8-year-old children among low-risk and CPS-referred parents. Mediational analyses supported the idea that the ABC intervention enhanced parents' sensitivity 7 years later indirectly via increases in parents' secure base script knowledge.
\end{abstract}

Keywords: attachment representations, early intervention, parental sensitivity

(Received 1 September 2020; revised 23 September 2020; accepted 26 September 2020)

Edward Zigler had a profound and lasting impact on the extent to which developmental research came to inform practice and policy. He brought an evidence-based developmental approach to his roles as the first director of the Head Start program, the director of the Office of Child Development, and chief of the US Children's Bureau. He also urged developmental scientists to take on the responsibility of considering how their research can be used to encourage the healthy development of children living in poverty (Zigler, 1998). Ed Zigler's work and the principles that he stood for have had a deep impact on our research examining the development of young children whose parents are facing many challenges, such as homelessness, neighborhood violence, and poverty. Although we do not address the life challenges confronting parents directly, we strive to help parents provide a safe, secure environment for their children through the parenting program we developed. As Zigler (1995) recognized, when parents and teachers can provide critical supports for children, children can thrive even though they may live in challenging conditions.

Over the past several decades, our group has developed and tested the Attachment and Biobehavioral Catch-up (ABC)

Author for Correspondence: Lee Raby, Department of Psychology, University of Utah, 380 S 1530 E, Salt Lake City, UT 84112 and Mary Dozier, Department of Psychological and Brain Sciences, University of Delaware, 108 Wolf Hall, Newark, DE, 19716; E-mail: lee.raby@psych.utah.edu; mdozier@psych.udel.edu

Cite this article: Raby KL, Waters TEA, Tabachnick AR, Zajac L, Dozier M (2021). Increasing secure base script knowledge among parents with Attachment and Biobehavioral Catch-up. Development and Psychopathology 33, 554-564. https:// doi.org/10.1017/S0954579420001765 intervention (Dozier \& Bernard, 2019). This brief intervention was developed to help parents provide sensitive, nurturing care for children who have experienced early adversity. ABC is an evidence-based intervention with multiple randomized controlled trials supporting the intervention's efficacy in promoting parenting quality and in enhancing children's biological and behavioral outcomes during infancy and early childhood (for a concise review, see Dozier \& Bernard, 2017). Of interest here is whether the $\mathrm{ABC}$ intervention results in sustained improvements in parents' behavior several years after they complete the intervention and, if so, what mechanisms may account for the long-term changes in parents' behavior. The present study draws on contemporary research from attachment theory and examines whether parents' cognitive scripts regarding attachment relationships mediate the effect of the ABC intervention on parents' sensitivity several years after completing the intervention.

\section{The secure base script}

One of the central propositions of attachment theory is that individuals construct a set of mental representations of attachment relationships based on their close interpersonal experiences (Bowlby, 1982). Waters and Waters (2006; see also Waters, Waters, \& Waters, in press) proposed that attachment-related representations are organized in the form of a cognitive script regarding the effectiveness of support afforded by attachment relationships in times of distress. Originating from work in cognitive psychology, the cognitive script is a mental schema summarizing the temporal-causal structure of a set of routine activities 
(Schank \& Abelson, 1977). According to Waters and Waters (2006), the secure base script contains eight central elements that form the basic temporal-causal structure for the successful resolution of distress through secure base use and support: (a) the attached individual is constructively engaged with the environment, (b) they encounter an obstacle or threat to exploration, (c) they signal distress to and seek support from an attachment figure, (d) the attachment figure is available and responds promptly with support, (e) the help is accepted, (f) the support provided by the attachment figure is effective in overcoming the challenge, $(\mathrm{g})$ the attachment figure provides comfort that effectively alleviates the attached individual's distress, and (h) the individual/dyad return to constructive engagement with the environment.

Waters and Waters (2006) also proposed a method for assessing knowledge of the secure base script. Specifically, the Attachment Script Assessment is a set of word prompts presented to participants with instructions to produce narratives. The wordprompt method derives from research on memory development (e.g., Waters, 1981). Each outline follows an implied story line, but individuals are free to use the words however they wish. The resulting narratives are then coded for the degree to which they include content reflecting the secure base script. Individuals who produce narratives that are organized around the elements of the secure base script are thought to have knowledge of the secure base script that is well consolidated and readily accessible. In contrast, narratives that do not contain these elements or that include content that is inconsistent with the secure base script (e.g., the attachment figure is the source of the distress) are thought to indicate a lack of knowledge of the secure base script (see also Waters \& Waters, in press).

A burgeoning body of research has supported the utility of the secure base script concept as well as the validity of the Attachment Script Assessment as a measure of adults' scripted attachment representations. For example, ratings of individuals' secure base script knowledge during this task have a moderately strong correlation with the ratings of individuals' coherence during the Adult Attachment Interview, the most widely used and well-validated measure of adults' attachment representations (Coppola, Vaughn, Cassibba, \& Costantini, 2006; Dykas, Woodhouse, Cassidy, \& Waters, 2006; Hawkins, Madigan, Moran, \& Pederson, 2015; Steele et al., 2014; Waters \& Rodrigues-Doolabh, 2001). In addition, adults' knowledge of the secure base script has its origins, at least in part, in childhood experiences with parents (Nivison et al., 2020; Schoenmaker et al., 2015; Steele et al., 2014; Waters, Ruiz, \& Roisman, 2017) and appears to guide adults' behavior when interacting with their own children. Specifically, parents' secure base script knowledge is associated with the degree to which they interact with their young children in a sensitive manner (Bárrig-Jó et al., 2016; Coppola et al., 2006; Hawkins et al., 2015; Huth-Bocks, Muzik, Beeghly, Earls, \& Stacks, 2014; Trumbell, Hibel, Mercado, \& Posada, 2018; Waters, Raby, Ruiz, Martin, \& Roisman, 2018). Consistent with these findings, parents' knowledge of the secure base script is also positively associated with the likelihood that their children develop secure attachment representations, as assessed through observations of children's attachment behaviors or narrative-based assessments (Bost et al., 2006; Monteiro, Veríssimo, Vaughn, Santos, \& Bost, 2008; Vaughn et al., 2007; Veríssimo \& Salvaterra, 2006; Waters, Bosman, Vandevivere, Dujardin, \& Waters, 2015; Waters et al., 2018; Wong et al., 2011).

Altogether, these studies provide promising evidence for the significance of parents' secure base script knowledge for the quality of the parent-child relationship, but to our knowledge, findings have been limited to parental behavior when interacting with young children (i.e., birth to age 5 years). The lack of research regarding the role of parents' secure base script knowledge for guiding parental behavior when interacting with older children is notable given the normative changes in the attachment relationship during childhood. Although school-age children continue to rely on their parents for secure base support, the parentchild relationship during middle childhood is also characterized by the need to support children's desires for autonomy and their capacities for increasingly independent emotion regulation (Bosmans \& Kerns, 2015; Sroufe, 1979). For this reason, the parent-child attachment relationship has been characterized as a partnership during the middle childhood years (Bowlby, 1982; Marvin, Britner, \& Russell, 2016; Waters, Kondo-Ikemura, Posada, \& Richters, 1991). Thus, it is critical to understand whether parents' secure base script knowledge shapes their ability to adapt to new demands and interact with their children in a sensitive, responsive manner during the middle childhood period.

In addition, most studies that have examined the implications of parents' secure base script knowledge for parenting behavior have involved community samples with low- or normative-risk backgrounds. Evaluating whether parents' secure base script knowledge shapes key parenting outcomes among high-risk families is another crucial next step for research in this area. These questions are in line with Zigler's (1998) emphasis on the value of applying basic developmental theory and research to understand the needs of vulnerable children and families as well as the principle from developmental psychopathology that research on normal and abnormal populations and processes are complementary and mutually informative (Cicchetti, 1984; Sroufe, 1990).

\section{Intervening to change secure base script knowledge}

Longitudinal research has demonstrated that secure base script knowledge is relatively stable across time (for a review, see Waters \& Roisman, 2019). That said, attachment representations and cognitive scripts are theorized to be flexible and capable of adjusting in response to novel experiences (Bowlby, 1988; Schank \& Abelson, 1977). The test-retest correlation of the ratings of adults' secure base script knowledge across intervals of up to 20 years is approximately $r=.50$ (Vaughn et al., 2006; Waters et al., 2017, 2019; in press; Waters et al. (in pressb), which suggests there is both substantial stability and meaningful changes in adults' understanding of and access to the secure base script. Moreover, emerging research has highlighted the potential for modification in individuals' knowledge of the secure base script. Waters et al. (2019) reported that adolescents' knowledge of the secure base script changed as a function of natural fluctuations in family stress. Specifically, after accounting for the moderate levels of year-to-year stability in secure base script knowledge, the frequency of recent but minor stressful life events was associated with increased knowledge of the secure base script during middle childhood and early adolescence. When interpreting this finding, the authors proposed that these minor stressful life events may have provided adolescents with opportunities to practice the secure base script by seeking out, and receiving support from, their attachment figures which in turn led to a greater understanding and access to the secure base script. In addition, De Winter, Salemink, and Bosmans (2018) provided experimental evidence suggesting that children's use of the secure base script during the Attachment Script Assessment could be modified, at least temporarily, with a brief cognitive interpretation bias training. 
Psychotherapy has been proposed to be another type of experience that can encourage shifts towards secure mental representations (e.g., Bowlby, 1988). A limited number of studies have evaluated this idea by assessing adults' attachment representations via autobiographical interviews, with mixed results (for a review see Fearon, Groh, Bakermans-Kranenburg, van IJzendoorn, \& Roisman, 2016). To our knowledge, whether adults' knowledge of the secure base script can be experimentally altered with an attachment-based intervention has not yet been examined. Intervention research has the potential to test hypotheses about the causal processes that contribute to individuals' secure base script knowledge. Therefore, as noted by Waters and Roisman (2019), examining change through a randomized clinical trial represents a critical next step for secure base script research.

\section{The Attachment and Biobehavioral Catch-up intervention}

$\mathrm{ABC}$ is a brief, 10-session home-visiting intervention that was designed to promote the healthy development of infants and toddlers who have experienced early adversity by helping parents provide responsive care for their young children (Dozier \& Bernard, 2019). ABC focuses on changing parenting at the behavioral level. Specifically, the ABC intervention encourages parents to respond with nurturance when children are distressed, to follow their children's lead when children are not distressed and are exploring their environments, and to reduce behaviors that are intrusive or frightening to young children. ABC targets these parenting behaviors because they are crucial to the development of secure attachments with parents as well as children's capacities for effective behavioral and biological regulation (Ainsworth, Blehar, Waters, \& Wall, 2015; Gunnar \& Donzella, 2002; Sroufe, 1996). One of the key components in promoting change in parents' behaviors is providing parents with live feedback while they are interacting with their young children during the intervention sessions (Caron, Bernard, \& Dozier, 2018). These "in-the-moment comments" help parents recognize and accurately interpret their children's signals and respond to these signals in a sensitive manner.

Several randomized controlled trials have supported the efficacy of the $\mathrm{ABC}$ intervention for changing both parental behavior and child outcomes during infancy and early childhood. For example, young children whose parents received the $\mathrm{ABC}$ intervention exhibited improvements in attachment security (Bernard et al., 2012), regulation of diurnal cortisol levels (Bernard, Dozier, Bick, \& Gordon, 2015; Bernard, Hostinar, \& Dozier, 2015), emotional and behavioral regulation (Labella, Lind, Sellers, Roben, \& Dozier, 2020; Lewis-Morrarty, Dozier, Bernard, Moore, \& Terraciano, 2012; Lind, Bernard, Ross, \& Dozier, 2014; Lind, Bernard, Yarger, \& Dozier, 2020; Lind, Raby, Carron, Roben, \& Dozier, 2017), along with other outcomes (Bernard, Lee, \& Dozier, 2017; Lind et al., 2020; Raby, Freedman, Yarger, Lind, \& Dozier, 2019). In addition, the $\mathrm{ABC}$ intervention promoted increases in parental sensitivity among diverse groups of parents (Bick \& Dozier, 2013; Raby et al., 2019; Yarger, Bernard, Caron, Wallin, \& Dozier, 2019; Yarger, Hoye, \& Dozier, 2016).

A critical next step is examining the degree to which the effects of the ABC intervention on parenting behavior are sustained over time. Follow-up assessments of the efficacy of the ABC intervention that extend beyond infancy and early childhood would provide valuable information about whether this early intervention results in long-term improvements in parents' sensitivity to their children's signals. This is especially important given the normative changes in parent-child relationship dynamics as children enter middle childhood (Bowlby, 1982; Marvin et al., 2016; Waters et al., 1991). Sensitively responding to children's signals during middle childhood may represent a novel challenge relative to what parents originally learned during the $\mathrm{ABC}$ intervention when their children were infants.

Related to this, a better understanding is also needed of the mechanisms that may account for ABC's long-term effects on parents' behavior. Adults' mental representations of attachment are a likely mechanism. According to attachment theory, attachment representations guide parents' responses to their children, and can adjust when new information related to attachment relationships is encountered (Bowlby, 1988). To be clear, altering parents' attachment representations is not an explicit goal of the ABC intervention. Nonetheless, it is possible that parents' mental representations of attachment relationships are tacitly updated as a result of the parenting-related information and interactive feedback parents receive during the intervention sessions. In other words, although the $\mathrm{ABC}$ intervention focuses on parental behavior, parents may construct a deeper understanding of the secure base script by internalizing the information about secure base relationships that is included in the intervention - namely, the importance of attachment figures providing effective comfort when children are distressed, supporting children's exploration when they not distressed, and not behaving in ways that are inconsistent with the secure base script (e.g., by being frightening or intrusive) - as well as by reflecting on the effects of their own increased responsiveness to their children's needs.

\section{The present study}

The current study assessed secure base script knowledge among parents who had been referred to Child Protective Services (CPS) when their children were infants due to risk for child maltreatment. Parents had been randomly assigned to receive either $\mathrm{ABC}$ or a control intervention when their children were infants. Approximately 7 years after parents completed the interventions, the parents' knowledge of the secure base script was assessed using the Attachment Script Assessment and parents were observed interacting with their 8-year-old children. In addition, a low-risk sample of parents and their 8-year-old children were recruited from the community to participate in these assessments.

The present study addressed three research questions. The first was whether the $\mathrm{ABC}$ intervention is effective in promoting understanding of the secure base script among parents who had previously been referred to CPS. The second question was whether parents' knowledge of the secure base script is associated with parents' sensitivity when they are interacting with their 8 -year-old children among CPS-referred and low-risk parents. Building on the previous two questions, our third research question was whether the $\mathrm{ABC}$ intervention indirectly effects parental sensitivity by increasing parents' knowledge of the secure base script.

\section{Method}

\section{Participants}

The current study included a high-risk and a low-risk group of parents. The high-risk group included 94 parents from a major city in the Mid-Atlantic region of the United States who had been referred to CPS following allegations of maltreatment 
Table 1. Demographic characteristics of parents

\begin{tabular}{|c|c|c|c|}
\hline & ABC intervention $(n=43)$ & Control intervention $(n=51)$ & Low-risk parents $(n=79)$ \\
\hline \multicolumn{4}{|l|}{ Parental educational attainment } \\
\hline Less than high school degree & $44.2 \%$ & $20.4 \%$ & $5.1 \%$ \\
\hline High school degree or GED & $39.5 \%$ & $62.7 \%$ & $27.8 \%$ \\
\hline Some college/trade school & $14.0 \%$ & $15.7 \%$ & $36.7 \%$ \\
\hline Baccalaureate degree & $0.0 \%$ & $0.0 \%$ & $20.3 \%$ \\
\hline Postgraduate degree & $2.3 \%$ & $2.0 \%$ & $10.1 \%$ \\
\hline \multicolumn{4}{|l|}{ Family income } \\
\hline$<\$ 10,000$ & $14.3 \%$ & $23.9 \%$ & $1.4 \%$ \\
\hline$\$ 10,000-\$ 19,999$ & $35.7 \%$ & $34.8 \%$ & $12.3 \%$ \\
\hline$\$ 20,000-\$ 29,999$ & $19.0 \%$ & $15.2 \%$ & $17.8 \%$ \\
\hline$\$ 30,000-\$ 39,999$ & $11.9 \%$ & $21.7 \%$ & $17.8 \%$ \\
\hline$\$ 40,000-\$ 59,999$ & $14.3 \%$ & $2.2 \%$ & $15.1 \%$ \\
\hline$\$ 60,000-\$ 99,999$ & $4.8 \%$ & $2.2 \%$ & $19.2 \%$ \\
\hline$\$ 100,000+$ & $0.0 \%$ & $0.0 \%$ & $16.4 \%$ \\
\hline \multicolumn{4}{|l|}{ Parental race/ethnicity } \\
\hline African-American & $62.8 \%$ & $68.6 \%$ & $48.1 \%$ \\
\hline White/non-Hispanic & $18.6 \%$ & $2.0 \%$ & $21.5 \%$ \\
\hline Hispanic & $14.0 \%$ & $23.5 \%$ & $22.8 \%$ \\
\hline Biracial & $4.7 \%$ & $5.9 \%$ & $3.8 \%$ \\
\hline Other & $0.0 \%$ & $0.0 \%$ & $3.8 \%$ \\
\hline \multicolumn{4}{|l|}{ Parental age (years) } \\
\hline Mean $(S D)$ & $33.8(6.5)$ & $34.6(8.1)$ & $35.1(5.8)$ \\
\hline
\end{tabular}

ABC: Attachment and Biobehavioral Catch-up

when their children were infants. The CPS-referred parents were enrolled in a program intended to divert children from foster care and were then referred to the current study by CPS caseworkers. Inclusion criteria for the study were that the child was under the age of 2 years, was living with their birth parents, and did not have a serious medical condition that interfered with locomotion (e.g., cerebral palsy). Following referral, a project coordinator contacted families to explain the study, obtained consent from interested parents during an initial home visit, and then used a random number generator to randomly assign families to receive either the ABC intervention or a control intervention. At the time, the families were initially enrolled in the study, children's ages ranged from 1.0 to 25.3 months ( $M=9.7$ months; $43 \%$ female). After completing the interventions, families participated in a series of follow-up research visits during early childhood. An additional round of follow-up data was collected in a second phase, which was completed when the children were in middle childhood. In particular, the data for the present study were collected when the children were 8 years old ( $M=8.4$ years, $S D=0.3$ years; $45 \%$ female). At the time of this follow-up assessment, parents' ages ranged from 22.7 to 52.5 years ( $M=34.2$ years). All parents who participated in this assessment were female, except for two males.

The low-risk group of parents included 79 parents recruited when their children were 8 years old $(M=8.5$ years, $S D=0.3$ years; $47 \%$ female). These families did not have a history of involvement with CPS and were not assigned to receive either $\mathrm{ABC}$ or a control intervention. All of the low-risk parents were female.

Demographic characteristics of the low-risk parents and the CPS-referred parents assigned to the two intervention conditions are provided in Table 1. Written informed consent was obtained from parents at the 8-year assessment, and the study was approved by the University of Delaware Institutional Review Board.

\section{Interventions}

Both the $\mathrm{ABC}$ intervention and the control intervention were manualized, consisted of ten sessions that were one hour in duration, and were delivered in weekly intervals in families' homes by trained interventionists (referred to as "parent coaches"). In addition, CPS-referred parents also received one booster session a few months prior to the follow-up assessment when children were 8 years old. During this booster session, parent coaches reviewed the parenting behaviors that were the focus of the intervention the parents had originally been assigned to when their children were infants.

\section{Attachment and Biobehavioral Catch-up}

The ABC intervention targeted three parental behaviors: promoting parents' nurturing responses when children are distressed; increasing parents' sensitivity by following their children's lead 
when children are not distressed; and decreasing intrusive, harsh, and potentially frightening parental behaviors (Dozier \& Bernard, 2019). During intervention sessions, parent coaches discussed research evidence included in the manual that supported the importance of these parental behaviors for children's development, used video examples and video feedback to illustrate the target behaviors, and provided parents with in-the-moment comments that highlighted when parents responded to children with nurturance and sensitivity (Caron et al., 2018).

\section{Control intervention}

The Developmental Education for Families intervention was adapted from an evidence-based home visiting program that focused on educating parents about children's cognitive, motor, and language development (Ramey, Yeates, \& Short, 1984). Parent coaches provided parents with information about parenting behaviors that help children achieve developmental milestones and encouraged parents to engage in activities that support children's development in these domains. Video feedback was used to review the parenting skills and demonstrate how children benefited from the activities.

\section{Measures}

\section{Secure base script knowledge}

Parents completed the adult version of the Attachment Script Assessment (Waters \& Waters, 2006; in press) when children were 8 years old. Parents were asked to tell six stories. Three stories focused on hypothetical parent-child relationships ("Baby's Morning," "Doctor's Office," and "Trip to the Park"), and the other three stories concerned hypothetical adult-adult relationships ("The Accident," "Jane and Bob's Camping Trip," and "An Afternoon Shopping"). The order that the story prompts were presented to the parents was counterbalanced. For each story, parents were provided with the title of a story and a set of word prompts that consisted of 12 words organized in three columns. For each story, the word prompts outlined an implied storyline. Parents were asked to tell the best story they could tell and to include as much detail as possible. Parents were told that the prompt-word outlines provided a general guide for what the story was supposed to be about but that they did not have to include all the words and that they could change the order of the words if they wished.

Parents' narratives were digitally recorded and subsequently transcribed verbatim. Two of the parent-child relationship stories ("Baby's Morning" and "Doctor's Office") and two of the adultadult relationship stories ("The Accident" and "Jane and Bob's Camping Trip") were designed to elicit stories with attachment-related content. The other two stories were designed to elicit narratives that did not contain attachment-related content and were included to reduce the risk of demand characteristics biasing participants' narratives. Each of the four attachmentfocused stories was coded for the degree to which the secure base script was evident using a 7-point rating scale (Waters \& Rodrigues-Doolabh, 2004; see also in press). Narratives that provided richly detailed content regarding secure base script received the highest scores (6-7), narratives that included modest evidence of the secure base script received moderately high scores (4-5), narratives that were event-focused and contained minimal to no evidence of the secure base script received moderately low scores (3), and narratives that were disjointed or contained atypical content that is inconsistent with the secure base script received the lowest scores (1-2). All stories were independently scored by two trained research assistants, and the intra-class correlations were between 0.92 and 0.96 . For each story, a final score was calculated by averaging the two coders' scores, with the exception that differences between the two coders' scores that were greater than half a scale point were resolved via conferencing. Coders were blind to whether the parents were included in the low-risk or CPS-referred group, and which intervention condition the CPS-referred parents originally had been assigned to receive, as well as the ratings of parental sensitivity. The ratings for the four stories were significantly correlated ( $r$ s between .33 and .59), which is consistent with the assumption that the four ratings reflect a single construct (Waters et al., 2015). A composite measure of parents' knowledge of the secure base script was created by averaging the four ratings $(\alpha=0.77)$.

\section{Parental sensitivity}

As described by Zajac, Raby, and Dozier (2018), parents and children were observed interacting for 5 minutes in a laboratory setting when children were 8 years old. Parents and children were asked to work together to plan a hypothetical birthday party for the child. Specifically, parent-child dyads were instructed to pretend that the child's birthday was the upcoming weekend and to plan the perfect birthday party for the child as if there were no limits on where they could go, what they could do, and who they could invite. The research assistant confirmed the dyads understood the instructions and then left them in a room for the 5-minute conversation.

Parental sensitivity during this interaction was assessed using a 5 -point scale adapted from procedures used in previous studies (e.g., NICHD Early Child Care Research Network, 1999). The rating scale captured a parent's ability to follow the child's lead by: (a) encouraging the child's contributions to the conversation (e.g., asking the child open-ended questions, showing an active interest in the child's ideas, and flexibly joining in the child's interpretation of the prompt without concern about the right way to have the discussion) and (b) responding to the child's cues in an appropriate manner (e.g., contingent vocalizations throughout the discussion and matching the child's affect and energy levels). All Parent $\times$ Child interactions were double-coded by two trained research assistants who were blind to whether the parents were included in the low-risk or CPS-referred group, which intervention condition the CPS-referred parents originally had been assigned to receive, and parents' secure base script knowledge ratings. The intra-class correlation for the two coders' ratings was 0.90 . Because large discrepancies in the sensitivity ratings assigned by the two coders were infrequent, the ratings were not conferenced. Instead, a composite measure of parental sensitivity was created by averaging the two coders' ratings. Parent $\times$ Child interactions were not collected for five parents (two low-risk parents, two parents who had received the control intervention, and one parent who had received $\mathrm{ABC}$ ). In order to account for these missing data, all parameters involving parental sensitivity were estimated using full information likelihood within Mplus version eight (Muthén \& Muthén, 1998-2017).

\section{Results}

\section{Preliminary analyses}

We first tested for potential differences regarding the demographic characteristics of the CPS-referred parents who were randomly assigned to the two intervention conditions. Parents who 


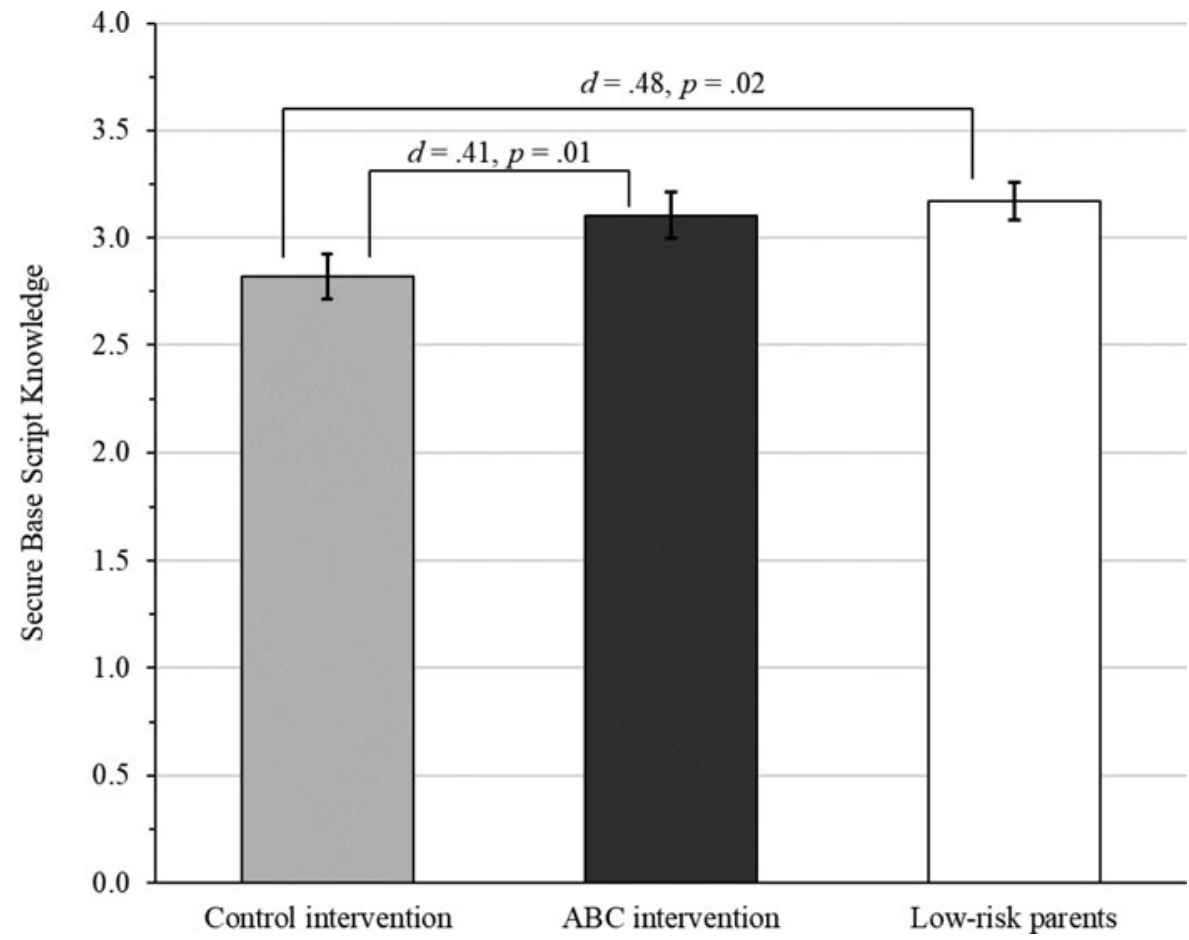

Figure 1. Secure base script knowledge for parents referred to child protective services who had received a control intervention, parents referred to child protective services who had received Attachment and Biobehavioral Catch-up ( $A B C)$ group, and low-risk parents. Parents' educational attainment, family income, and parents' race/ethnicity were included as covariates. Differences between the groups are represented using Cohen's (1992) $d$ statistic as a measure of effect size. had received $\mathrm{ABC}$ did not significantly differ from parents who received the control intervention with respect to their educational attainment, family income, or age at the time of the middle childhood assessment (see Table 1). However, the distribution of parental race/ethnicity classifications did differ across the two interventions $\left(\chi^{2}=8.05, p=.045\right)$. Parents who received ABC were more likely to be White/non-Hispanic than parents who received the control intervention. For that reason, a binary variable capturing parental race/ethnicity $(1=$ White/non-Hispanic, $0=$ otherwise) was included as a covariate in the focal analyses.

We also explored potential differences regarding the demographic characteristics between the low-risk and CPS-referred parents. Low-risk parents had higher educational attainment than CPS-referred parents $(r=.52, p<.001)$ and higher family income than CPS-referred parents $(r=.52, p<.001)$ and were more likely to be White/non-Hispanic than CPS-referred parents $(r=.17, p=.029)$. Low-risk parents and CPS-referred parents did not differ with respect to parental age.

These demographic variables also were associated with parents secure base script knowledge and parental sensitivity in the combined sample of 173 parents. Specifically, parents' educational attainment was positively associated with their secure base script knowledge $(r=.42, p<.001)$ and their parental sensitivity $(r=.25$, $p=.001)$. Family income also was positively associated with parents' secure base script knowledge $(r=.37, p<.001)$ and their parental sensitivity $(r=.38, p<.001)$. White/non-Hispanic parents exhibited greater secure base script knowledge $(r=.24, p=.002)$ and greater sensitivity $(r=.28, p<.001)$ than parents of other racial/ethnic groups. Parental age was not significantly associated with parents' secure base script knowledge or their parental sensitivity.

\section{The effect of the $A B C$ intervention on secure base script knowledge}

Differences in the level of secure base script knowledge between low-risk parents, parents who received $\mathrm{ABC}$, and parents who received the control intervention were examined using analyses of variance that controlled for parents' educational attainment, family income, and parents' race/ethnicity. There was a main effect of parental group, $F(2,173)=3.83, p=.024$ (see Figure 1 for graphical depiction of data). Pairwise comparisons indicated that parents who had received the $\mathrm{ABC}$ intervention exhibited more secure base script knowledge than parents who received the control intervention, $F(1,94)=2.30, p=.012$; low-risk parents exhibited more secure base script knowledge than CPS-referred parents who had received the control intervention, $F(1,130)=$ $5.77, p=.018$; in contrast, low-risk parents did not differ significantly from CPS-referred parents who had received ABC in their level of secure base script knowledge, $F(1,117)=0.08, p$ $=.675$.

\section{The association between secure base script knowledge and sensitive parenting}

A linear regression analysis indicated that parents' knowledge of the secure base script was positively associated with their observed parental sensitivity: $B=0.72, S E=0.12, \beta=.56, p<.001$. In other words, parents with higher secure base script knowledge interacted with their children in a more sensitive manner than parents with less knowledge of the secure base script. This association was robust to controlling for parental race/ethnicity, educational attainment, and income, $B=0.38, S E=0.09, \beta=.33, p<.001$. In addition, this association was not conditional on parental CPS involvement, with secure base script knowledge positively correlated with sensitive parenting for CPS-referred parents as well as low-risk parents (see Figure 2).

\section{Indirect effect of $A B C$ on parental sensitivity via secure base script knowledge}

The evidence that: (a) the $\mathrm{ABC}$ intervention promoted CPS-referred parents' knowledge of the secure base script and 

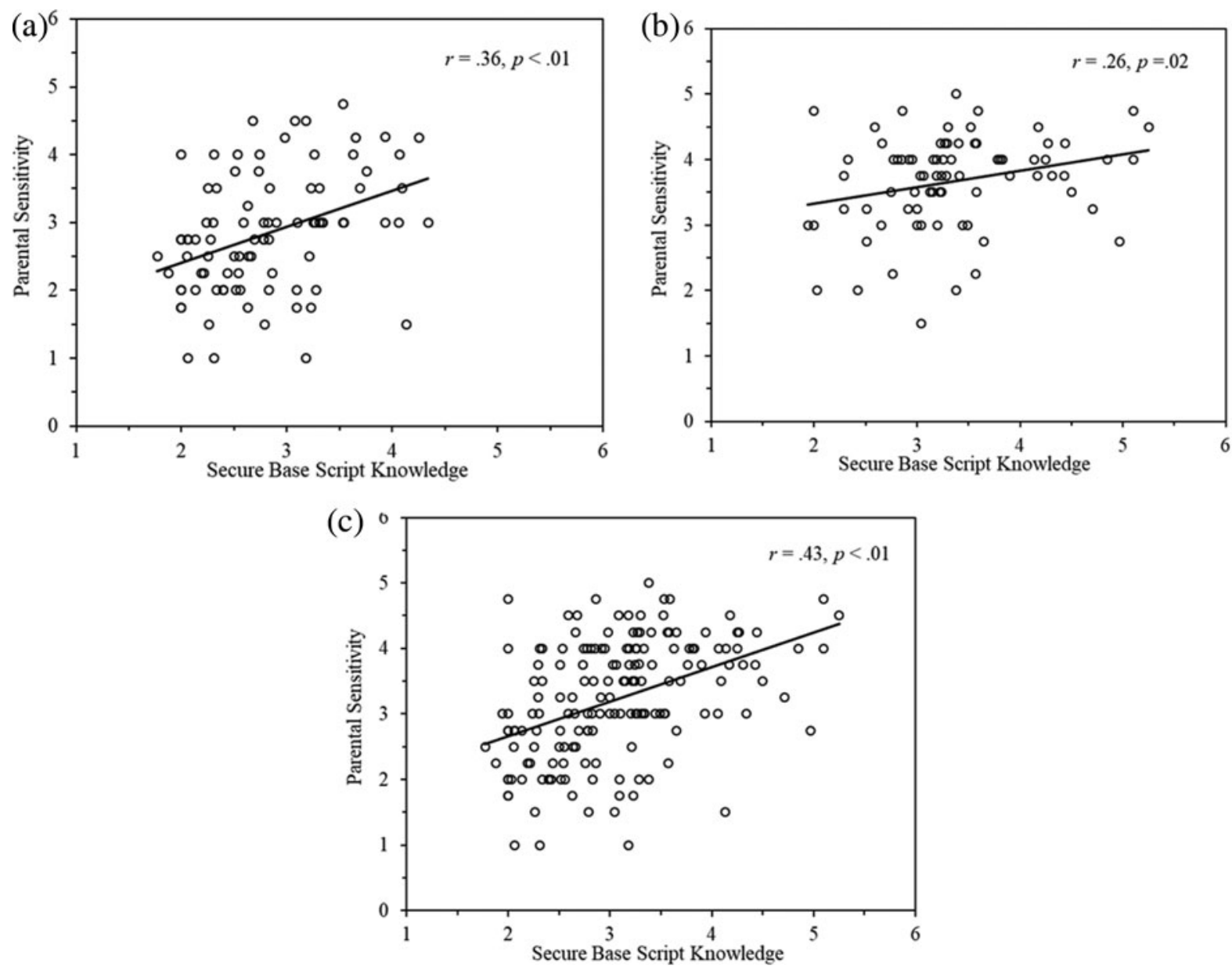

Figure 2. The association between secure base script knowledge and parental sensitivity for (A) parents who were referred to child protective services, (B) low-risk parents, and (C) the combined sample.

(b) secure base script knowledge was positively associated with parental sensitivity among CPS-referred parents supported the possibility that parents' secure base script knowledge mediated the intervention's effect on parental sensitivity. This indirect effect was evaluated using the "MODEL INDIRECT" command in Mplus. Because the low-risk parents did not participate in the interventions, only the CPS-referred parents were included in these analyses. First, the model was run without covariates. Results indicated that the $\mathrm{ABC}$ intervention did not have a significant overall effect on parental sensitivity $(B=0.02, S E=0.18, \beta$ $=.01, p=.90)$. However, there was a significant indirect effect of $\mathrm{ABC}$ on parental sensitivity via secure base script knowledge ( $B$ $=0.16, S E=0.08, \beta=.09, p=.042$ ). Results were similar when covariates were included in the model. Specifically, the ABC intervention did not have a significant overall effect on parental sensitivity $(B=-0.07, S E=0.19, \beta=-.04, p=.72)$, but the indirect effect via secure base script knowledge was significant $(B=0.21$, $S E=0.09, \beta=.12, p=.022$; see Figure 3 ). Thus, the ABC intervention resulted in increases in parental sensitivity indirectly via its effect on parents' knowledge of the secure base script.

\section{Discussion}

The findings from this randomized controlled trial demonstrated that low-risk parents and CPS-referred parents who received the
ABC intervention exhibited greater secure base script knowledge than CPS-referred parents who had been randomized to receive a control intervention. Moreover, levels of secure base script knowledge did not differ significantly between low-risk parents and CPS-referred parents who had received the ABC intervention. Secure base script knowledge was positively associated with parents' sensitivity during interactions with their 8-year-old children, an effect seen among low-risk and CPS-referred parents. Finally, the mediational analyses indicated that the $\mathrm{ABC}$ intervention indirectly enhanced parents' sensitivity via increases in parents' secure base script knowledge.

There is robust evidence indicating that the $\mathrm{ABC}$ intervention promotes sensitive parenting and enhances children's biological and behavioral wellbeing during infancy and early childhood (Dozier \& Bernard, 2017; Dozier \& Bernard, 2019). Emerging evidence suggests that $\mathrm{ABC}$ has sustained effects on children's outcomes during middle childhood, including effects on neural activity, hypothalamic-pituitary-adrenal axis regulation, autonomic nervous system functioning, and perceived attachment security (Bick, Palmwood, Zajac, Simons, \& Dozier, 2018; Garnett, Bernard, Hoye, Zajac, \& Dozier, 2020; Tabachnick, Raby, Goldstein, Zajac, \& Dozier, 2019; Valadez, Tottenham, Tabachnick, \& Dozier, 2020; Zajac, Raby, \& Dozier, 2019). The results of the current study offer novel evidence that the $A B C$ intervention also has sustained effects on parents. Specifically, 


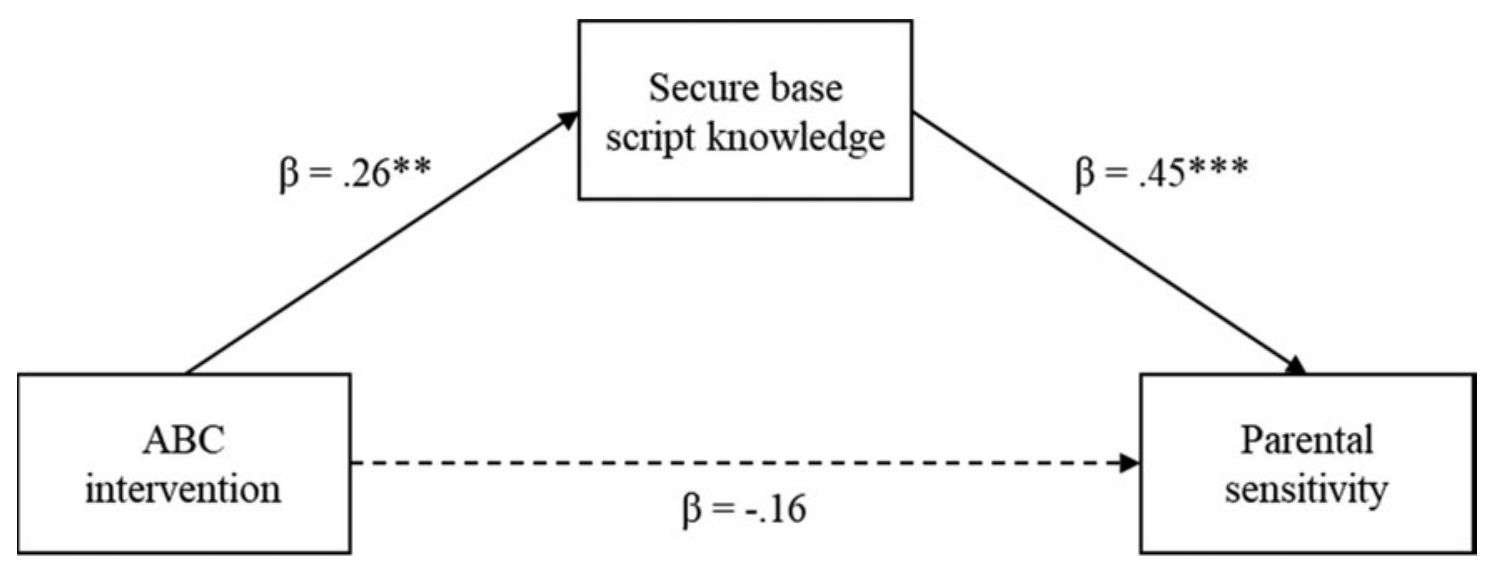

Figure 3. The indirect effect of the Attachment and Biobehavioral Catch-up (ABC) intervention on parental sensitivity via increases in parents' secure base script knowledge. Values represent standardized regression coefficients. Covariates (parent educational attainment, family income, and parent racial/ethnicity) were included in the model but are not depicted for simplicity. $N=94 .{ }^{\star \star} p<.01 .{ }^{\star \star \star} p<.001$.

the $\mathrm{ABC}$ intervention results in increases in parents' secure base script knowledge, which in turn promote parents' sensitivity to their children's signals 7 years after parents completed the intervention. In this way, these findings offer additional evidence that the beneficial effects of the $\mathrm{ABC}$ intervention are not limited to the years immediately following the intervention and instead persist at least into middle childhood.

The evidence that the $\mathrm{ABC}$ intervention improved parents' secure base script knowledge is consistent with the idea that attachment representations and cognitive scripts are malleable and can be modified by novel experiences (Bowlby, 1988; Schank \& Abelson, 1977; see also Waters et al., 2019). An important direction for future research will be to explicate precisely when and how parents' understandings of the secure base script are altered by the $A B C$ intervention. One possibility is that parents immediately construct a deeper understanding of the secure base script as a result of the parenting-related information and individualized feedback they receive during the $\mathrm{ABC}$ intervention sessions and these changes in secure base script knowledge lead to corresponding improvements in parental sensitivity. Another possibility is that the $\mathrm{ABC}$ intervention first alters parents' behaviors, which in turn creates a new parent-child relationship dynamic (e.g., parents are more sensitive to children's signals and children are more comfortable using their parents as a secure base), and these new experiences with their children eventually lead to increases in parents' secure base script knowledge. Additional longitudinal studies are needed to evaluate these two possibilities given that the study assesses parents' secure base script knowledge once approximately 7 years after parents completed the $\mathrm{ABC}$ intervention. Studies that repeatedly assess parents' secure base script knowledge and parenting behavior beginning shortly after families complete the $\mathrm{ABC}$ intervention would offer valuable insights about the time course of the effects of the $\mathrm{ABC}$ intervention on parents' behaviors and secure base script knowledge as well as the potential transactional processes between these two parental outcomes.

To our knowledge, the current study provides the first evidence that secure base script knowledge shapes how parents interact with their children during middle childhood. Despite the normative changes in parent-child dynamics during this period, parents' secure base script knowledge nonetheless appears to guide parents' responses to school-age children's signals in a manner similar to what has been observed with parents of young children (e.g., Coppola et al., 2006; Waters et al., 2018). In addition, although the low-risk and CPS-referred families included in the current study differed from one another with respect to a number of demographic variables, parents' secure base script knowledge was positively associated with parental sensitivity for both groups of parents. This result is consistent with the notion that attachment representations predict theoretically relevant behavioral outcomes for individuals from diverse cultural groups (Mesman, van IJzendoorn, \& Sagi-Schwartz, 2016; see also Haltigan et al., 2014). This generalizability of the association between secure base script knowledge and parental sensitivity across the two groups of families also supports the validity of the narrative-based Attachment Script Assessment among samples with relatively low levels of formal education.

Unique strengths of the study include the observational measure of parental sensitivity, the independent assessment of parents' secure base script knowledge using the Attachment Script Assessment, and the focus on a unique sample of families at risk for maltreatment. The study's longitudinal design allowed for a test of whether the $\mathrm{ABC}$ intervention has sustained effects on parents. In addition, the current study's use of a controlled trial design allows for confidence in the causal effects of the $\mathrm{ABC}$ intervention on parents' secure base script knowledge and parental behavior. Because parents' secure base script knowledge was not assessed prior to completing the intervention, we cannot rule out the possibility that randomization was not successful, meaning that parents who received the $\mathrm{ABC}$ and control interventions differed in their secure base script knowledge prior to being randomized to receive one of the two interventions. That said, the parents who received the $\mathrm{ABC}$ intervention did not differ from parents who received the control intervention with respect to many key demographic variables, and other analyses with this group of parents have reported a lack of significant differences in parents' attachment states of mind and parents' sensitivity assessed prior to receiving the interventions (Zajac et al., 2019).

In conclusion, the current study demonstrates that the $\mathrm{ABC}$ intervention has a relatively long-lasting impact on parental sensitivity by promoting parents' understanding of the secure base script. The current study contributes to our basic understanding of the malleability of parents' mental scripts regarding attachment relationships as well as the significance of these scripts for shaping 
parental behavior among diverse groups of families. These findings also extend our understanding of the relatively long-term beneficial impacts of an early home-visiting intervention for at-risk families. We are hopeful that the current study is in keeping with ideals espoused by Zigler (1998) of rigorous developmental science that meaningfully contributes to improving the lives of vulnerable children and families.

Acknowledgment. We thank the children and families who participated in this research. We also gratefully acknowledge the support of child protection agencies in Philadelphia.

Funding Statement. This research was supported by National Institute of Mental Health grant R01MH074374 to Mary Dozier. The content is solely the responsibility of the authors and does not necessarily represent the official views of the National Institutes of Health.

Conflicts of Interest. None.

\section{References}

Ainsworth, M. D. S., Blehar, M. C., Waters, E., \& Wall, S. (2015). Patterns of attachment: A psychological study of the strange situation (classic edition). New York: Routledge.

Bárrig-Jó, P., Nóblega, M., Del Prado, J. N., Conde, G., Carbonell, O. A., \& De Litvan, M. A. (2016). Attachment representations and maternal sensitivity in low socioeconomic status mothers. International Journal of Psychological Studies, 8, 202-214. doi:10.5539/ijps.v8n3p202

Bernard, K., Dozier, M., Bick, J., \& Gordon, M. K. (2015). Intervening to enhance cortisol regulation among children at risk for neglect: Results of a randomized clinical trial. Development and Psychopathology, 27, 829841. doi:10.1017/S095457941400073X

Bernard, K., Dozier, M., Bick, J., Lewis-Morrarty, E., Lindhiem, O., \& Carlson, E. (2012). Enhancing attachment organization among maltreated infants: Results of a randomized clinical trial. Child Development, 83, 623-636. doi:10.1111/j.1467-8624.2011.01712.x

Bernard, K., Hostinar, C. E., \& Dozier, M. (2015). Intervention effects on diurnal cortisol rhythms of child protective services-referred infants in early childhood: Preschool follow-up results of a randomized clinical trial. Journal of the American Medical Association Pediatrics, 169, 112-119. doi:10.1001/jamapediatrics.2014.2369

Bernard, K., Lee, A. H., \& Dozier, M. (2017). Effects of the ABC intervention on foster children's receptive vocabulary: Follow-up results from a randomized controlled trial. Child Maltreatment, 22, 174-179. doi:10.1177/ 1077559517691126

Bick, J., \& Dozier, M. (2013). The effectiveness of an attachment-based intervention in promoting foster mothers' sensitivity toward foster infants. Infant Mental Health Journal, 34, 95-103. doi:10.1002/imhj.21373

Bick, J., Palmwood, E. N., Zajac, L., Simons, R., \& Dozier, M. (2018). Early parenting intervention and adverse family environments affect neural function in middle childhood. Biological Psychiatry, 85, 326-335. doi:10.1016/ j.biopsych.2018.09.020

Bosmans, G., \& Kerns, K. A. (2015). Attachment in middle childhood: Progress and prospects. In G. Bosmans \& K. A. Kerns (Eds.), Attachment in middle childhood: Theoretical advances and new directions in an emerging field. New Directions for Child and Adolescent Development, 148, 1-14. doi:10.1002/cad.20100

Bost, K. K., Shin, N., McBride, B. A., Brown, G. L., Vaughn, B. E., Coppola, G., ... North, B. (2006). Maternal secure base scripts, children's attachment security, and mother-child narrative styles. Attachment \& Human Development, 8, 241-260. doi:10.1080/14616730600856131

Bowlby, J. (1982). Attachment and loss. Vol. 1: Attachment (2nd ed.). New York: Basic Books.

Bowlby, J. (1988). Developmental psychiatry comes of age. American Journal of Psychiatry, 145, 1-10. doi:10.1176/ajp.145.1.1

Caron, E. B., Bernard, K., \& Dozier, M. (2018). In vivo feedback predicts parent behavior change in the attachment and biobehavioral catch-up intervention. Journal of Clinical Child \& Adolescent Psychology, 47, S35S46. doi:10.1080/15374416.2016.1141359

Cicchetti, D. (1984). The emergence of developmental psychopathology. Child Development, 55, 1-7. doi:10.2307/1129830

Cohen, J. (1992). A power primer. Psychological Bulletin, 112(1), 155-159. https://doi.org/10.1037/0033- 2909.112.1.155

Coppola, G., Vaughn, B. E., Cassibba, R., \& Costantini, A. (2006). The attachment script representation procedure in an Italian sample: Associations with adult attachment interview scales and with maternal sensitivity. Attachment \& Human Development, 8, 209-219. doi:10.1080/ 14616730600856065

De Winter, S., Salemink, E., \& Bosmans, G. (2018). Interpretation bias in middle childhood attachment: Causal effects on attachment memories and scripts. Behaviour Research and Therapy, 102, 16-24. doi:10.1016/ j.brat.2017.12.004

Dozier, M., \& Bernard, K. (2017). Attachment and biobehavioral catch-up: Addressing the needs of infants and toddlers exposed to inadequate or problematic caregiving. Current Opinion in Psychology, 15, 111-117. doi:10.1016/j.copsyc.2017.03.003

Dozier, M., \& Bernard, K. (2019). Coaching parents of vulnerable infants: The attachment and biobehavioral catch-up approach. New York: Guilford Press.

Dykas, M. J., Woodhouse, S. S., Cassidy, J., \& Waters, H. S. (2006). Narrative assessment of attachment representations: Links between secure base scripts and adolescent attachment. Attachment \& Human Development, 8, 221240. doi:10.1080/14616730600856099

Fearon, R. P., Groh, A. M., Bakermans-Kranenburg, M. J., van IJzendoorn, M. H., \& Roisman, G. I. (2016). Attachment and developmental psychopathology. In D. Cicchetti (Ed.), Developmental psychopathology: Theory and method (3rd ed., pp. 325-384). Hoboken, NJ: Wiley.

Garnett, M., Bernard, K., Hoye, J., Zajac, L., \& Dozier, M. (2020). Parental sensitivity mediates the sustained effect of attachment and biobehavioral catch-up on cortisol in middle childhood: A randomized clinical trial. Psychoneuroendocrinology, 121, 10480. doi:10.1016/j.psyneuen.2020.104809

Gunnar, M. R., \& Donzella, B. (2002). Social regulation of the cortisol levels in early human development. Psychoneuroendocrinology, 27, 199-220. doi:10.1016/S0306-4530(01)00045-2

Haltigan, J. D., Leerkes, E. M., Wong, M. S., Fortuna, K., Roisman, G. I., Supple, A. J., ... Plamondon, A. (2014). Adult attachment states of mind: Measurement invariance across ethnicity and associations with maternal sensitivity. Child Development, 85, 1019-1035. doi:10.1111/cdev.12180

Hawkins, E., Madigan, S., Moran, G., \& Pederson, D. (2015). Mediating and moderating processes underlying the association between maternal cognition and infant attachment. Journal of Applied Developmental Psychology, 39, 24-33. doi:10.1016/j.appdev.2015.04.001

Huth-Bocks, A. C., Muzik, M., Beeghly, M., Earls, L., \& Stacks, A. M. (2014) Secure base scripts are associated with maternal parenting behavior across contexts and reflective functioning among trauma-exposed mothers. Attachment \& Human Development, 16, 535-556. doi:10.1080/ 14616734.2014.967787

Labella, M. H., Lind, T., Sellers, T., Roben, C. K. P., \& Dozier, M. (2020). Emotion regulation among children in foster care versus birth parent care: Differential effects of an early home-visiting intervention. Journal of Abnormal Child Psychology, 48, 995-1006. doi:10.1007/s10802-020-00653-4

Lewis-Morrarty, E., Dozier, M., Bernard, K., Terraciano, S. M., \& Moore, S. V. (2012). Cognitive flexibility and theory of mind outcomes among foster children: Preschool follow-up results of a randomized clinical trial. Journal of Adolescent Health, 51, 17-22. doi:10.1016/j.jadohealth. 2012.05.005

Lind, T., Bernard, K., Ross, E., \& Dozier, M. (2014). Intervention effects on negative affect of CPS-referred children: Results of a randomized clinical trial. Child Abuse and Neglect, 38, 1459-1467. doi:10.1016/ j.chiabu.2014.04.004

Lind, T., Bernard, K., Yarger, H., \& Dozier, M. (2020). Promoting compliance in children referred to child protective services: A randomized clinical trial. Child Development, 91, 563-576. doi:10.1111/cdev.13207

Lind, T., Raby, K. L., Caron, E. B., Roben, C. K. P., \& Dozier, M. (2017). Enhancing executive functioning among toddlers in foster care with an attachment-based intervention. Development and Psychopathology, 29, 575-586. doi:10.1017/S0954579417000190 
Lind, T., Raby, K., Goldstein, A., Bernard, K., Caron, E., Yarger, H., ... Dozier, M. (2020). Improving social-emotional competence in internationally adopted children with the attachment and biobehavioral catch-up intervention. Development and Psychopathology. Advance online publication. doi:10.1017/S0954579420000255

Marvin, R. S., Britner, P. A., \& Russell, B. S. (2016). Normative development: The ontogeny of attachment in childhood. In J. Cassidy \& P. R. Shaver (Eds.), Handbook of attachment: Theory, research, and clinical applications (3rd ed., pp. 273-290). New York: Guilford Press.

Mesman, J., van IJzendoorn, M. H., \& Sagi-Schwartz, A. (2016). Cross-cultural patterns of attachment: Universal and contextual dimensions. In J. Cassidy \& P. R. Shaver (Eds.), Handbook of attachment: Theory, research, and clinical application (3rd ed., pp. 852-1068). New York, NY: Guilford Press.

Monteiro, L., Veríssimo, M., Vaughn, B. E., Santos, A. J., \& Bost, K. K. (2008). Secure base representations for both fathers and mothers predict children's secure base behavior in a sample of Portuguese families. Attachment \& Human Development, 10, 189-206. doi:10.1080/14616730802113711

Muthén, L. K., \& Muthén, B. O. (1998-2017). Mplus User's guide (Eighth edition). Los Angeles, CA: Muthén \& Muthén..

NICHD Early Child Care Research Network. (1999). Child care and parentchild interaction in the first 3 years of life. Developmental Psychology, 35, 1399-1413. doi:10.1037/0012-1649.35.6.1399

Nivison, M. D., Facompré, C. R., Raby, K. L., Simpson, J. A., Roisman, G. I., \& Waters, T. E. A. (2020). Childhood abuse and neglect are prospectively associated with scripted attachment representations in young adulthood. Development and Psychopathology, 1-13. doi:10.1017/S0954579420000528

Raby, K. L., Freedman, E., Yarger, H. A., Lind, T., \& Dozier, M. (2019). Enhancing the language development of toddlers in foster care by promoting foster parents' sensitivity: Results from a randomized control trial. Developmental Science, 22, e12753. doi:10.1111/desc.12753

Ramey, C. T., Yeates, K. O., \& Short, E. J. (1984). The plasticity of intellectual development: Insights from preventative intervention. Child Development, 55, 1913-1925. doi:10.2307/1129938

Schank, R., \& Abelson, R. (1977). Scripts, plans, goals, and understanding: An inquiry into human knowledge structures. Hillsdale, NJ: Lawrence Erlbaum.

Schoenmaker, C., Juffer, F., van IJzendoorn, M. H., Linting, M., van der Voort, A., \& Bakermans-Kranenburg, M. J. (2015). From maternal sensitivity in infancy to adult attachment representations: A longitudinal adoption study with secure base scripts. Attachment \& Human Development, 17, 241-256. doi:10.1080/14616734.2015.1037315

Sroufe, L. A. (1979). The coherence of individual development: Early care, attachment, and subsequent developmental issues. American Psychologist, 34, 834-841. DO: 10.1037/0003-066X.34.10.834

Sroufe, L. A. (1990). Considering normal and abnormal together: The essence of developmental psychopathology. Development and Psychopathology, 2, 335-348. doi:10.1017/S0954579400005769

Sroufe, L. A. (1996). Emotional development. New York: Cambridge University Press.

Steele, R. D., Waters, T. E. A., Bost, K. K., Vaughn, B. E., Truitt, W., Waters, H. S., ... Roisman, G. I. (2014). Caregiving antecedents of secure base script knowledge: A comparative analysis of young adult attachment representations. Developmental Psychology, 50, 2526-2538. doi:10.1037/a0037992

Tabachnick, A. R., Raby, K. L., Goldstein, A., Zajac, L., \& Dozier, M. (2019). Effects of an attachment-based intervention in infancy on children's autonomic regulation during middle childhood. Biological Psychology, 143, 22-31. doi:10.1016/j.biopsycho.2019.01.006

Trumbell, J. M., Hibel, L. C., Mercado, E., \& Posada, G. (2018). The impact of marital withdrawal and secure base script knowledge on mothers' and fathers' parenting. Journal of Family Psychology, 32, 699-709. doi:10.1037/fam0000402

Valadez, E. A., Tottenham, N., Tabachnick, A. R., \& Dozier, M. (2020). Early parenting intervention effects on brain responses to maternal cues among high-risk children. The American Journal of Psychiatry, 177, 818-826. doi:10.1176/appi.ajp.2020.20010011

Vaughn, B. E., Coppola, G., Veríssimo, M., Monteiro, L., Santos, A. J., Posada, G., ... North, B. (2007). The quality of maternal secure-base scripts predicts children's secure-base behavior at home in three sociocultural groups. International Journal of Behavioral Development, 31, 65-76. doi:10.1177/ 0165025407073574
Vaughn, B. E., Veríssimo, M., Coppola, G., Bost, K. K., Shin, N., McBride, B., Korth, B. (2006). Maternal attachment script representations: Longitudinal stability and associations with stylistic features of maternal narratives. Attachment \& Human Development, 8, 199-208. doi:10.1080/ 14616730600856024

Veríssimo, M., \& Salvaterra, F. (2006). Maternal secure-base scripts and children's attachment security in an adopted sample. Attachment \& Human Development, 8, 261-273. doi:10.1080/14616730600856149

Waters, H. S. (1981). Organizational strategies in memory for prose: A developmental analysis. Journal of Experimental Child Psychology, 32, 223-246. doi:10.1016/0022-0965(81)90078-3

Waters, T. E. A., Bosman, G., Vandevivere, E., Dujardin, A., \& Waters, H. S. (2015). Secure base representations in middle childhood across two cultures: Associations with parental attachment representations and maternal reports of behavior problems. Developmental Psychology, 51, 1013-1025. doi: $10.1037 / \mathrm{a} 0039375$

Waters, T. E. A., Facompré, C. R., Dagan, O., Martin, J., Johnson, W. F., Young, E. S., ... Roisman, G. I. (in pressb). Convergent validity and stability of secure base script knowledge from young adulthood to midlife. Attachment \& Human Development.

Waters, T. E. A., Facompré, C. R., Van de Walle, M., Dujardin, A., De Winter, S., Heylen, J., ... Bosmans, G. (2019). Stability and change in secure base script knowledge during middle childhood and early adolescence: A 3-year longitudinal study. Developmental Psychology, 55, 2379-2388. doi: $10.1037 /$ dev0000798

Waters, T. E. A., Fraley, R. C., Groh, A. M., Steele, R. D., Vaughn, B. E., Bost, K. K., .. Roisman, G. I. (2015). The latent structure of secure base script knowledge. Developmental Psychology, 51, 823-830. doi:10.1037/ $\operatorname{dev} 0000012$

Waters, E., Kondo-Ikemura, K., Posada, G., \& Richters, J. E. (1991). Learning to love: Mechanisms and milestones. In M. R. Gunnar, \& L. A. Sroufe (Eds.), The Minnesota symposia on child psychology, Vol. 23. Self processes and development (pp. 217-255). Hillsdale, NJ: Lawrence Erlbaum Associates, Inc.

Waters, T. E. A., Raby, K. L., Ruiz, S. K., Martin, J., \& Roisman, G. I. (2018). Adult attachment representations and the quality of romantic and parentchild relationships: An examination of the unique contributions of coherence of discourse and secure base script knowledge. Developmental Psychology, 54, 2374-2381. doi:10.1037/dev0000607

Waters, H. S., \& Rodrigues-Doolabh, L. (2001, April). Are attachment scripts the building blocks of attachment representations? Narrative assessment of representations and the AAI. Paper presented at the biennial meeting of the Society for Research in Child Development, Minneapolis, MN.

Waters, H. S., \& Rodrigues-Doolabh, L. M. (2004). Narrative assessment of adult attachment representations: The scoring of secure base script content. Unpublished manuscript, Department of Psychology, State University of New York at Stony Brook, Stony Brook, NY.

Waters, T. E. A., \& Roisman, G. I. (2019). The secure base script concept: An overview. Current Opinion in Psychology, 25, 162-166. doi:10.1016/ j.copsyc.2018.08.002

Waters, T. E. A., Ruiz, S. K., \& Roisman, G. I. (2017). Origins of secure base script knowledge and the developmental construction of attachment representations. Child Development, 88, 198-209. doi:10.1111/cdev.12571

Waters, H. S., \& Waters, E. (2006). The attachment working models concept: Among other things, we build script-like representations of secure base experiences. Attachment \& Human Development, 8, 185-197. doi:10.1080/ 14616730600856016

Waters, H. S., \& Waters, T. E. A. (in press). Measuring attachment representations as secure base script knowledge: The prompt-word outline method in adulthood, adolescence, and middle childhood. To appear. In E. Waters, B. E. Vaughn, \& H. S. Waters (Eds.), Measuring attachment. New York: Guilford Press.

Waters, H. S., Waters, T. E. A., \& Waters, E. (in press). From internal working models to script-like attachment representations. To appear. In R. A. Thompson, J. A. Simpson, \& L. J. Berlin (Eds.), Attachment: The fundamental questions. New York: Guilford Press.

Wong, M., Bost, K. K., Shin, N., Veríssomo, M., Maia, J., Monteiro, L., ... Vaughn, B. (2011). Preschool children's mental representations of attachment: Antecedents 
in their secure base behaviors and maternal attachment scripts. Attachment and Human Development, 13, 489-502. doi:10.1080/14616734.2011.602256

Yarger, H. A., Bernard, K., Caron, E. B., Wallin, A., \& Dozier, M. (2019). Enhancing parenting quality for young children adopted internationally: Results of a randomized controlled trial. Journal of Clinical Child \& Adolescent Psychology, 49, 378-390. doi:10.1080/15374416.2018.1547972

Yarger, H. A., Hoye, J. R., \& Dozier, M. (2016). Trajectories of change in attachment and biobehavioral catch-up among high-risk mothers: A randomized clinical trial. Infant Mental Health Journal, 5, 525-536. doi:10.1002/imhj.21585

Zajac, L., Raby, K. L., \& Dozier, M. (2018). Attachment state of mind and childhood experiences of maltreatment as predictors of sensitive care from infancy through middle childhood: Results from a longitudinal study of parents involved with child protective services. Development and Psychopathology, 31, 113-125. doi:10.1017/S0954579418001554

Zajac, L., Raby, K. L., \& Dozier, M. (2019). Sustained effects on attachment security in middle childhood: Results from a randomized clinical trial of the attachment and biobehavioral catch-up (ABC) intervention. Journal of Child Psychology and Psychiatry, 61, 417-424. doi:10.1111/ jcpp. 13146

Zigler, E. (1995). Meeting the needs of children in poverty. American Journal of Orthopsychiatry, 65, 6-9. doi:10.1037/h0085067

Zigler, E. (1998). A place of value for applied and policy studies. Child Development, 69, 532-542. doi:10.1111/j.1467-8624.1998.tb06206.x 